\title{
Numerical Analysis and Control Study on Surrounding Rock Deformation of Deep Soft Rock Roadway
}

\author{
Enbing $\mathrm{Yi}^{1,2, *}$ \\ ${ }^{1}$ State Key Laboratory of The Gas Disaster Detecting, Preventing and Emergency Controlling, Chongqing 400037, China \\ ${ }^{2}$ China Coal Technology and Engineering Group Chongqing Research Institute, Chongqing 400037, China
}

\begin{abstract}
Aiming at the problem of large-scale deformation of the track and alleys in the East Second Mining Area, the numerical analysis method is used to analyze the stress and deformation law of the roadway. The results show that the critical depth of the roadway deformation is $800 \mathrm{~m}$, the shear stress of the deep roadway is about $8.7 \mathrm{MPa}$ in the left and right shoulders, and the vertical stress increases sharply in the range of $0 \sim 5.5 \mathrm{~m}$ from the center of the roadway, and is $6 \sim$ from the center of the roadway. The peak value is reached within $8 \mathrm{~m}$, the plastic zone of the roadway roof is $2.6 \mathrm{~m}$, the left and right plastic zones are $5.2 \mathrm{~m}$ and $5.4 \mathrm{~m}$, respectively, and the plastic zone of the floor is $6.1 \mathrm{~m}$. This result can provide a basis for the design parameters of deep soft rock roadway support. The engineering practice proves that the support design effectively controls the strong deformation of the roadway and achieves better support effect.
\end{abstract}

\section{Introduction}

Aiming at the control problems of soft rock roadways in deep wells, a lot of researches have been conducted on the deformation mechanism and support of soft rock roadways ${ }^{[1]}$. Domestic systematic research work on soft rock roadway support started in 1958, and many problems arising from deep well soft rock roadway support have become more prominent in coal mines. Zhang Zhenquan ${ }^{[2-3]}$ systematically analyzed and summarized the deformation and failure characteristics of this kind of roadway in response to the problem of deep high-stress soft rock roadway support, and proposed the combined support measures of bolting, wire mesh and cable injection. Literature ${ }^{[4-5]}$ proposed a new type of composite support technology system suitable for deep well soft rock, so that the overall stability of the surrounding rock has been significantly strengthened. References $^{[6]}$ used numerical simulation methods to simulate the soft rock roadway support scheme based on actual geological conditions, and obtained specific support parameters to provide a design basis for the support scheme. In the support theory, there are lithology transformation theory, axial variation theory, joint support theory, anchor shotcrete-arc plate support theory, loose circle support theory, primary and secondary bearing area support theory, stress control theory, anchor rod The surrounding rock strength strengthening theory of support, soft rock engineering mechanics support and other theories are currently difficult to solve the problem of large rheology and large deformation of deep well soft rock roadway only from the theoretical level. It needs to be comprehensively researched and solved by combining various research methods on site. In this paper, based on the actual engineering geological conditions, the numerical simulation method is used to study the specific parameters of the surrounding rock deformation of the soft rock roadway in deep wells, and it is applied to the field practice to effectively control the strong deformation of the roadway and obtain a better support effect. It is a soft rock with similar conditions Roadway support provides a reference.

\section{Project Overview}

According to field survey data under a mine, the high-stress soft-rock roadway in the mine has a large amount of deformation and a fast deformation speed, which has affected the normal use of the roadway, especially when it is affected by driving and mining. According to the field test, the shrinkage rate of the tunnel section is generally about $32 \%$, and the local shrinkage reaches more than $65 \%$. For example, the track roadway in the east second and south mining area needs to be undercovered once every three months. The annual displacement and deformation of the roadway is 1.1 1.5 $\mathrm{m}$, and the annual shrinkage and deformation rate of the cross section is about $24 \% \sim 36 \%$; The volume is close to $1.5 \sim 2.0 \mathrm{~m}$, and the annual shrinkage deformation of the cross section reaches $37.5 \% \sim 64.75 \%$. The elevation of the track roadway in the East Second South mining area is $-790 \mathrm{~m} \sim-960 \mathrm{~m}$, local cracks are developed, short-term dripping phenomenon occurs in some places, the roof is seriously sinking, the two gangs are seriously contracted,

*Corresponding author: Enbing Yi; yienbing95@163.com 
the bottom drum volume is large, and the roadway section is seriously contracted Safe Production. Based on the actual geological conditions in the range of $50 \mathrm{~m}$ before and after the B64 geological point of the track roadway in the East Second South mining area, this paper studies and analyzes the causes of the surrounding rock deformation of the roadway, provides a basis for the support design, controls the large roadway deformation, and ensures the safe transportation of the roadway.

\section{Numerical analysis of surrounding rock deformation}

\subsection{Numerical modeling}

According to the actual geological conditions of the track lanes in the East Second South mining area, the model is appropriately simplified, and the size of the model is established to be $60 \mathrm{~m}$ in length (x direction), $60 \mathrm{~m}$ in width (y direction), and $80 \mathrm{~m}$ in height ( $\mathrm{z}$ direction). Model grid of different sizes. The parameters of each rock layer in the model are revised and determined based on laboratory measurement data and site conditions.

The left and right boundaries of the model adopt the unilateral constraint condition of zero horizontal displacement, the bottom boundary adopts the full constraint condition that both horizontal displacement and vertical displacement are zero, the upper boundary adopts the stress boundary, and the uniform load is applied according to the thickness of the overlying rock layer. The relationship between model rock layers adopts the Coulomb-Moore model. An equivalent original rock stress load is applied to the upper boundary of the model, and its value is the self-weight stress of the overlying rock layer.

\subsection{Analysis of simulation results}

The vertical stress, horizontal stress and displacement of tunnels under different burial depths $(500 \mathrm{~m}, 600 \mathrm{~m}, 700$ $\mathrm{m}, 800 \mathrm{~m}, 900 \mathrm{~m}$, and $1000 \mathrm{~m}$ ) were simulated and studied, and the plastic zone of deformation and failure of the tunnel Scope changes.

(1) Stress and displacement analysis at the top of the roadway

By monitoring the vertical stress and displacement at specific points of the model, the distribution of stress and plastic failure zones under different burial depths is obtained.

As the mining depth increases, the vertical stress distribution of the surrounding rock of the roadway is approximately cylindrical and symmetrical. The top and bottom plates have tensile stress zones, and their range increases with the increase in mining depth. The distribution range of plastic zone of surrounding rock also increases with the increase of mining depth, and after the burial depth exceeds $800 \mathrm{~m}$, the destruction range of the plastic zone of the floor increases significantly. The burial depth of the track roadway in the East Second South mining area is about $800 \mathrm{~m}$. The roadway as a whole bears a large vertical stress. The vertical stress on the left and right sides of the roadway is approximately symmetrical. With large concentrated stress, the vertical stress of the right gang is approximately distributed with the left gang. A large stress-rising area is formed near the top and bottom corners of the roadway. Stress relaxation occurs in the surrounding rock and accompanied by tensile stress failure. The supporting structure cannot effectively prevent stress failure and invalidate the overall supporting structure of the roadway.

The shear stress concentration zone appears at a certain distance between the two shoulders and the two bottom corners of the roadway, and the shear stress reaches $8.7 \mathrm{MPa}$ in the surrounding rock deep in the left and right shoulders. In the low-stress area after shear failure, the top of the roadway and the bottom corners on both sides become the weakest support, and the roadway is unstable due to bottom corner failure.

The vertical stress distribution of roadway roof changes with the mining depth as shown in Figure 1.

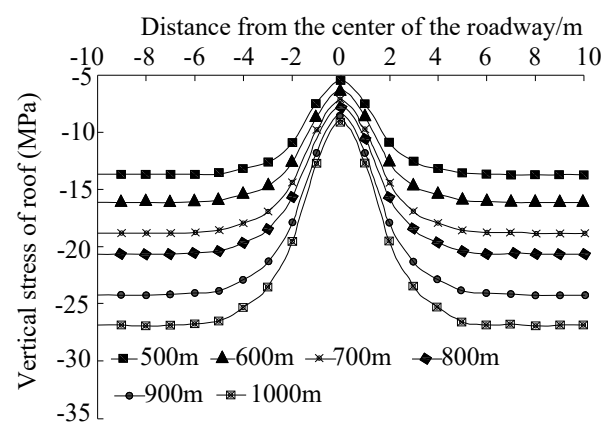

Fig. 1. Vertical stress distribution of roadway roof

As can be seen from Figure 1, the vertical stress of the roof after excavation increases gradually away from the center of the roadway, increases sharply within the range of $0 \sim 5.5 \mathrm{~m}$ from the center of the roadway, and peaks within the range of $6 \sim 8 \mathrm{~m}$ from the center of the roadway.

The vertical displacement of the roof of the tunnel is also funnel-shaped. The vertical displacement of the roof in the middle of the tunnel is the largest. The displacement of the roof decreases sharply within the range of $0 \sim 5.5 \mathrm{~m}$ from the center of the tunnel, and gradually returns to the initial state outside the range of 9 $\mathrm{m}$ from the center of the tunnel.

In summary, the vertical roof displacement and vertical stress are proportional to the mining depth. The vertical roof stress and roof vertical displacement correspond to each other, and they show abrupt changes within $5.5 \mathrm{~m}$ of the tunnel center.

(2) Stress and displacement analysis of the two sides of the roadway

Through comprehensive numerical analysis, it can be seen that the stress and displacement of the roadway rim increase with the increase of the depth of mining. As can be seen from Figure 2, the vertical stress of the roadway rim increases rapidly from 0 to $1.5 \mathrm{~m}$ from the center of the roadway to the maximum, indicating a $1.5 \mathrm{~m}$ range The inner rock is elasto-plastic, which is the range of 
rock layers to be controlled. The displacement of the two sides of the roadway is greater than the displacement of the roof and floor, indicating that in addition to the pressure from the rock body of the gang, the two gangs also bear the stress transmitted by the roof and floor to the gang.

According to the analysis of the stress and deformation characteristics of the gang, when the mining depth exceeds $800 \mathrm{~m}$, the stress and displacement changes show large changes. Therefore, $800 \mathrm{~m}$ is the critical mining depth for the rapid change of the surrounding rock. The buried depth of the track lanes in the East Second South Mining Area is also around 800-900 m.

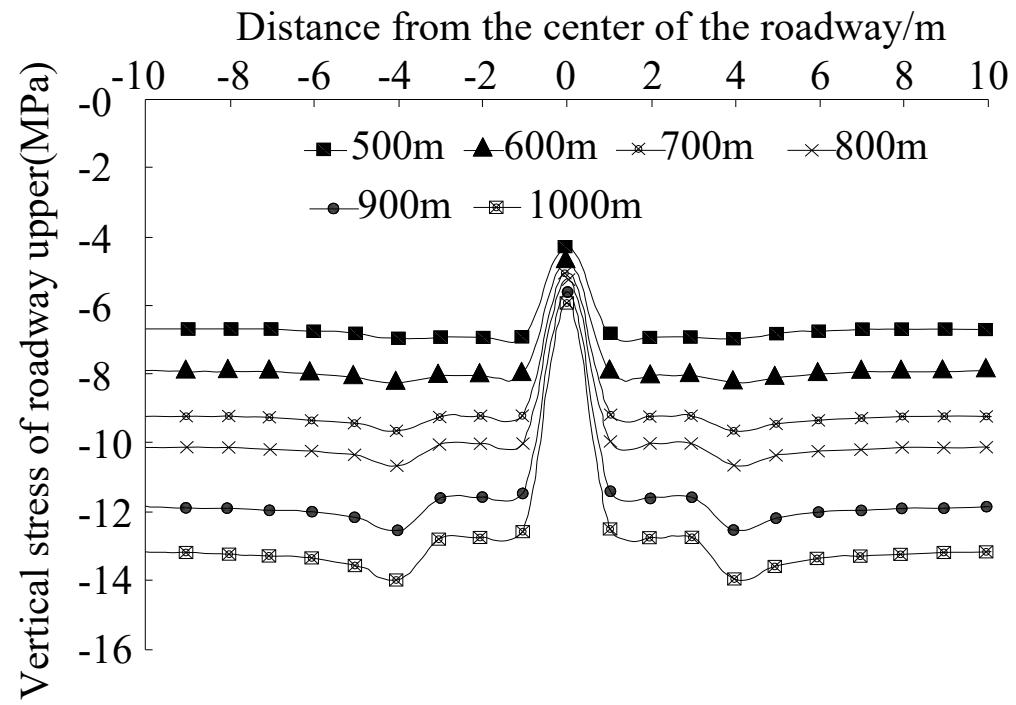

Fig. 2. Vertical stress distribution diagram of roadway side

(3) Analysis of plastic zone of roadway surrounding rock

The simulation results show that there is a huge plastic failure zone around the $800 \mathrm{~m}$ deep roadway, the plastic range of the roadway roof is $2.6 \mathrm{~m}$, the plastic zone of the left and right sides is $5.2 \mathrm{~m}$ and $5.4 \mathrm{~m}$, and the shear failure zone appears at the right corner of the roadway. The large-scale expansion of the tensile and shear composite failure zone caused the destruction of the roadway. The plastic failure of the floor of the roadway reached a maximum value of $6.1 \mathrm{~m}$. Due to the superimposition of the stress and seepage water on the roadway, the plastic zone was expanded widely. The floor area has destructive properties, which in turn leads to failure of the roadway support structure, resulting in instability of the roadway.

From Figure 3, it can be seen that the shear failure zone and the tensile failure zone of the roadway surrounding rock increase with the increase of the mining depth, and increase sharply after the burial depth is greater than $800 \mathrm{~m}$, so the $800 \mathrm{~m}$ burial depth is an inflection point. When the burial depth of the track roadway in the East Second South Mining Area exceeds $800 \mathrm{~m}$, the roadway is characterized by severe deformation and difficult maintenance. $800 \mathrm{~m}$ is the critical burial depth value of the rock roadway deformation. Therefore, the support of the track roadway in the East Second South Mining Area needs to be studied The new support system-the surrounding rock reserves the amount of deformation to allow local secondary reinforcement of the support system. The numerical simulation results can provide references for the selection of supporting system parameters and the design of supporting schemes.

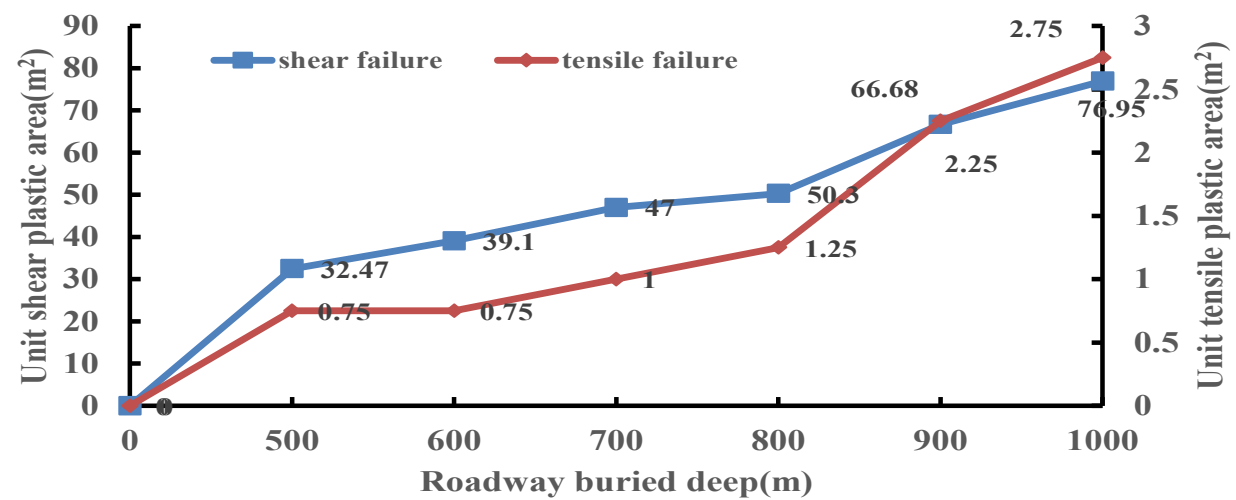

Fig. 3. Variation diagram of the distribution range of plastic zone 


\section{Analysis of engineering control effect}

According to the results of numerical analysis, based on a large number of actual rock pressure observations, the research has obtained the technical parameters and system suitable for the soft rock roadway support of the mine, that is, the surrounding rock deformation is reserved to allow pressure and then local secondary shotcreting reinforcement technology .

After the reserved deformation amount is used to make the local secondary reinforced anchor-mesh cable combined bearing arch support technology, the deformation process of the surrounding rock is gentle and gradually stabilizes. The maximum displacement of the roof and floor of the observation point of the tunnel is $56 \mathrm{~mm}$, and the maximum displacement of the two gangs is $22 \mathrm{~mm}$. The overall roadway is stable, and the deformation is extremely slow. The section of the roadway can meet the requirements of normal use, and ensure the safe transportation and efficient mining of the mine.

\section{Conclusion}

(1) As the roadway burial depth increases, the vertical stress distribution of the roadway surrounding rock is approximately symmetrically distributed in a cylindrical shape, and tensile stress zones appear on the roof and floor, and its range increases with the increase in mining depth. The damage range is obviously increased, and the degree of deformation and damage is increased.

(2) The vertical stress of the two sides of the roadway is approximately symmetrically distributed, and there is a large vertical stress concentration near $5 \mathrm{~m}$ outside the two sides. The shear stress is about $8.7 \mathrm{MPa}$ in the surrounding rock deep in the left and right shoulders, and is within $0 \sim 5.5 \mathrm{~m}$ from the center The vertical stress at the top increases sharply and reaches a peak within 6-8 m from the center of the tunnel.

(3) The horizontal stress at the side of the roadway increases sharply from 0 to $1.5 \mathrm{~m}$ from the center of the roadway to the maximum. The surrounding rock of 800 $\mathrm{m}$ deep roadway presents a huge plastic failure zone. The plastic range of the roadway roof is $2.6 \mathrm{~m}$, and the plastic zone of the left and right sides are $5.2 \mathrm{~m}$ and $5.4 \mathrm{~m}$, respectively. The large-scale expansion of the shear composite failure zone caused the destruction of the roadway. The plastic failure of the floor of the roadway reached a maximum of $6.1 \mathrm{~m}$. This result can provide a reference for the design of the support scheme.

(4) Combined with numerical simulation and comprehensive analysis, it is concluded that the deterioration of the surrounding rock at the top of the roadway is the main factor leading to the instability and destruction of the roadway. Here, the surrounding rock is broken, and it is affected by the fissure water and tectonic stress at the same time. When the force is lost, the stress is released here, which causes local stress concentration of the supporting structure and irregular deformation, which greatly reduces the bearing performance.

\section{Reference}

1. Bai,J.B.,Wang,X.Y.,Jia,M.K. (2008) Theory and application of supporting in deep soft roadways. Chinese Journal of Geotechnical Engineering,30:632-635.

2. Zhang,Z.Q. (2018) Stress Analysis and Support Research of Surrounding Rock in Deep High Stress Soft Rock Roadway. Coal Technology,37:49-51.

3. Ye,J.S,Jing,L.W.,Wang,Q.C. (2017) Stress Analysis and Support Research of Surrounding Rock in Deep High Stress Soft Rock Roadway. Coal Technology,36:108-110.

4. Sun,X.C., Yuan,Q., Shen,Y.S. (2017) Study on New Compound Support Technology for Deep Soft Rock Roadway.Coal Technology,36:31-33.

5. Zhang,G.H.,Li,F.Y. (2004) Research on control technology for broken and weak surrounding rocks in Xiaonan Mine. Coal Science and Technology,32: $1-4$.

6. Wang,H.T. (2018) Stress Analysis and Numerical Simulation of Support in Large Section Mining Roadway. Coal Technology,37: 47-49. 